\title{
PENGARUH KREDIT KETAHANAN PANGAN DAN ENERGI (KKPE) TERHADAP PRODUKSI AYAM RAS PEDAGING DI SUMATERA BARAT
}

\author{
Astri Aminova Putri ${ }^{1}$, Dwi Rachmina ${ }^{2}$, dan Anna Fariyanti ${ }^{3}$ \\ 1)Program Magister Sains Agribisnis, Sekolah Pascasarjana, Institut Pertanian Bogor \\ 2,3)Departemen Agribisnis, Fakultas Ekonomi dan Manajemen, Institut Pertanian Bogor \\ Jl. Kamper Wing 4 Level 5 Kampus IPB Dramaga, Indonesia \\ e-mail: ${ }^{1)}$ astriaminova86gmail.com
}

(Diterima 2 November 2019/Revisi 27 Desember 2019/Disetujui 31 Desember 2019)

\begin{abstract}
Food and energy security loan (KKPE) as the credit to support farmers to buy the input required to increase their agricultural produce. However, research showed that credit received by the farmers was not used to increase production optimally. The purpose of the study is to analyze the utilization of food and energy security loan (KKPE) and the effect on broiler production. The study was conducted in Padang Pariaman Regency, West Sumatera Province, as the broiler production centre. The data were collected through an interview with 85 farmers using questionnaires. Credit utilization was analyzed using tabulations. The analysis of the effect of credit on broiler production was analyzed by using the broiler production function. The results showed the (DOC), feed, vitamin, drugs, vaccines, and labour costs and invest in business equipment such as animal fodder, washing machine and repair. This research concludes that credit increases the production of broilers by 47,52 per cent.
\end{abstract}

Keywords: broilers, fungibility credit, KKPE

\begin{abstract}
ABSTRAK
Kredit ketahanan pangan dan energi (KKPE) merupakan kredit untuk mendukung permodalan peternak yang ditujukan untuk pengadaan input produksi dalam peningkatan produksi usahatani. Namun beberapa penelitian menunjukkan bahwa kredit yang diterima petani belum digunakan secara maksimal untuk peningkatan produksi. Penelitian ini bertujuan untuk menganalisis pemanfaatan KKPE dan pengaruhnya terhadap produksi ayam ras pedaging. Penelitian dilaksanakan di Kabupaten Padang Pariaman, Provinsi Sumatera Barat yang merupakan sentra produksi ayam ras pedaging. Pengumpulan data dilakukan melalui wawancara terhadap 85 peternak menggunakan kuisioner. Pemanfaatan KKPE usaha ayam ras pedaging dianalisis menggunakan tabulasi. Analisis pengaruh KKPE terhadap produksi ayam ras pedaging dilakukan dengan analisis fungsi produksi ayam ras pedaging. Hasil penelitian menunjukkan dari rata-rata jumlah kredit yang diterima peternak sebesar Rp. 57.116.000, tidak sepenuhnya dimanfaatkan untuk usaha ayam ras pedaging. Rata-rata pemanfaatan untuk ayam ras pedaging hanya sebesar 94,49 persen di antaranya dimanfaatkan untuk pembelian input ayam ras pedaging berupa bibit ayam (DOC), pakan, vitamin, vaksin, obat dan upah tenaga kerja serta menambah peralatan usaha seperti tempat pakan ternak, mesin cuci kandang dan perbaikan kandang. Dari penelitian ini menunjukkan bahwa kredit mampu meningkatkan produksi ayam ras pedaging sebesar 47,52 persen.
\end{abstract}

Kata kunci: ayam ras pedaging, KKPE, penyalahgunaan kredit

\section{PENDAHULUAN}

Kredit merupakan salah satu alternatif sumber modal yang berasal dari luar modal sendiri untuk mendukung permodalan petani diantaranya memperluas usaha (Cheng et al. 2011), pengadaan sarana prasarana produksi (Sekyi 2013) dan meningkatkan produksi (Udoka et al. 2016). Kredit ketahanan pangan dan energi (KKPE) merupakan kredit inves- 
tasi dan modal kerja yang ditujukan kepada petani dengan suku bunga disubsidi dan direalisasikan untuk pengembangan budidaya tebu, peternakan, tanaman pangan dan tanaman hortikultura. Penggunaan KKPE untuk pengembangan peternakan diantaranya untuk ayam ras pedaging dengan plafon kredit Rp. 100.000.000 per peternak dan suku bunga sebesar 6 persen, yang ditujukan untuk pengadaan bibit, pakan, obat, biaya operasional, sertifikasi lahan, asuransi ternak, dan biaya beban hidup (Kementerian Pertanian 2017).

Pentingnya penyaluran KKPE untuk ayam ras pedaging dikarenakan ayam ras pedaging memberikan kontribusi besar terhadap penyediaan daging nasional. Produksi daging tahun 2018 mencapai 3,26 juta ton dengan produksi daging ayam ras pedagang merupakan produksi tertinggi yaitu mencapai 65,68 persen. Produksi daging ayam ras pedaging terus mengalami peningkatan seperti ditunjukkan pada Gambar 1.

\section{Produksi (000 ton)}

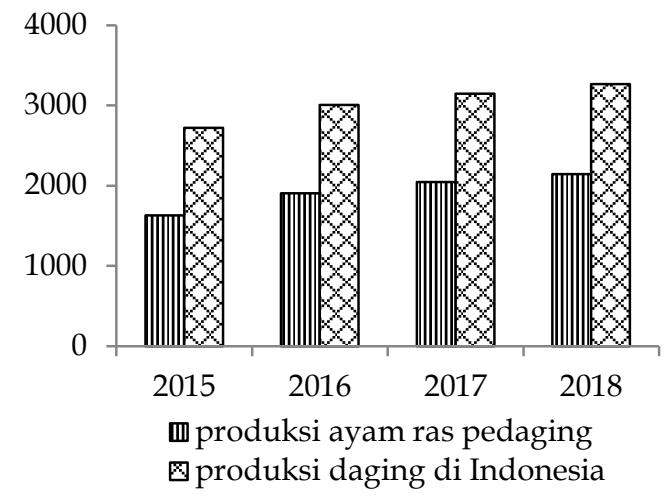

Gambar 1. Perkembangan Produksi Ayam Ras Pedaging dan Produksi Daging Nasional Sumber : Badan Pusat Statistik (2019)
Peningkatan produksi menunjukkan bahwa ayam ras pedaging berpotensi terus mengalami peningkatan produksi mengingat kebutuhan daging ayam ras pedaging terus meningkat karena perannya sebagai pengganti daging sapi dengan konsumsi mencapai $5,68 \mathrm{~kg} / \mathrm{kapita} /$ tahun untuk daging segar, dan $9,91 \mathrm{~kg} / \mathrm{kapita} /$ tahun untuk daging dari makanan jadi (Badan Pusat Statistik 2018). Tingginya konsumsi masyarakat terhadap daging ayam olahan dan daging segar menunjukkan pentingnya penyediaan daging ayam baik untuk konsumsi maupun bahan baku industri pengolahan berbahan baku daging ayam.

Sumatera Barat merupakan daerah yang unggul dalam jumlah produksi daging ayam ras pedaging. Kontribusi ayam ras pedaging terhadap penyediaan daging di Sumatera Barat mencapai 30,51 persen, sedangkan kontribusi daging ayam ras pedaging terhadap konsumsi daging menunjukkan kontribusi sebesar 42,98 persen (Badan Pusat Statistik 2019).

Produksi ayam ras pedaging menunjukkan fluktuasi produksi yang merupakan dampak ketidakpastian produksi akibat keterbatasan modal. Hasil survei menunjukkan peternak hanya mampu berproduksi 3-5 siklus per tahun, padahal usaha ayam ras pedaging dapat dilakukan mencapai 8 siklus per tahun. Keterbatasan modal menyebabkan penggunaan input ayam ras pedaging terutama pakan tidak digunakan sesuai anjuran. Keterbatasan modal juga menyebabkan peternak sulit mengembangkan usaha ayam ras pedaging. Oleh karena keterbatasan modal peternak, realisasi KKPE difokuskan untuk pengembangan ayam ras pedaging di

Tabel 1. Produksi Daging Ternak di Sumatera Barat Tahun 2015 - 2018

\begin{tabular}{|c|c|c|c|c|c|c|c|c|c|}
\hline \multirow[b]{2}{*}{ Tahun } & \multicolumn{8}{|c|}{ Produksi Daging (ton) dan Laju Produksi Ternak } & \multirow[b]{2}{*}{$\begin{array}{l}\text { Jumlah } \\
\text { Produksi } \\
\text { (ton) }\end{array}$} \\
\hline & Sapi & $\begin{array}{c}\text { Laju } \\
\text { Produksi }\end{array}$ & $\begin{array}{c}\text { Ayam Ras } \\
\text { Pedaging }\end{array}$ & $\begin{array}{c}\text { Laju } \\
\text { Produksi }\end{array}$ & $\begin{array}{l}\text { Ayam } \\
\text { Buras }\end{array}$ & $\begin{array}{c}\text { Laju } \\
\text { Produksi }\end{array}$ & $\begin{array}{l}\text { Ayam } \\
\text { Ras } \\
\text { Petelur }\end{array}$ & $\begin{array}{c}\text { Laju } \\
\text { Produksi }\end{array}$ & \\
\hline 2015 & 26. & & $28.521,00$ & & 6. & & $6.157,59$ & & \\
\hline 20 & & & & & & -0 & & & \\
\hline 2017 & $20.206,00$ & $-0,24$ & 20.4 & $-0,(\mathrm{r} \quad$ e & 4.9 & $0,($ & $6.731,00$ & 0 & 65. \\
\hline 2018 & $20.609,00$ & 0,02 & $20.663,15$ & 0,42 & $5.093,00$ & 0,24 & $6.791,00$ & $-0,09$ & $65.742,00$ \\
\hline
\end{tabular}

Sumber : Badan Pusat Statistik (2019) 
Kabupaten Padang Pariaman yang merupakan sentra produksi dengan produksi tertinggi kedua setelah Kabupaten Lima Puluh Kota yaitu 23,27 persen produksi ayam ras pedaging di Sumatera Barat.

Ketersediaan KKPE untuk mendukung pembiayaan usaha ayam ras pedaging menjadi penting karena usaha ayam ras pedaging merupakan usaha yang padat modal. Dibutuhkan modal besar diantaranya untuk penyediaan input berupa DOC dan pakan. Rahmah 2015; Ratnasari et al. 2015 mengungkapkan biaya pengadaan pakan ayam ras pedaging berkisar $60-70$ persen dari biaya produksi sedangkan biaya pengadaan DOC berkisar 28,80 persen dari biaya produksi (Bahari et al. 2012).

Sunarno et al. (2017) menyatakan bahwa peningkatan penggunaan input merupakan faktor yang berkontribusi terhadap pertumbuhan pertanian melalui peningkatan produksi. Hal ini dibuktikan pada hasil studi Derosari et al. 2014; Dewi et al. 2015; Dharmawan dan Karyani 2018 menyatakan bahwa pemanfaatan KKPE untuk usaha pertanian mampu meningkatkan produksi dengan menambah penggunaan input berupa bibit, pakan, anakan, dan tenaga kerja.

Peningkatan produksi usahatani akan optimal jika kredit digunakan untuk membiayai usahatani. Namun faktanya pemanfaatan kredit tidak hanya digunakan untuk usaha yang dibiayai kredit, tetapi juga untuk kebutuhan lainnya. Hasil temuan Derosari et al. (2014) menyatakan bahwa sebesar 24 persen kredit yang diterima peternak sapi dimanfaatkan untuk usaha selain sapi dan konsumsi. Tidak jauh berbeda dengan studi Ijioma dan Charles (2015) yang mengkaji penyaluran kredit di Nigeria menyatakan bahwa petani memanfaatkan kredit untuk kebutuhan rumah tangga sebesar 46,67 persen. Bahkan studi Iski et al. (2015) menyatakan bahwa kredit dimanfaatkan untuk konsumsi mencapai 79,10 persen.

Tingginya persentase pemanfaatan kredit untuk kebutuhan selain usahatani yang dibiayai kredit ternyata berpengaruh terhadap kinerja usahatani. Hasil studi Dewi et al. (2015) menunjukkan pemanfaatan KKPE untuk usahatani padi hanya sebesar 44.60 persen. Pemanfaatan tersebut menunjukkan kredit tidak dimanfaatkan sepenuhnya untuk usahatani padi, sehingga pengaruh pemanfaatan KKPE terhadap produksi hanya sebesar 18,93 persen, sedangkan hasil studi Bashir et al. (2010) menunjukkan bahwa peningkatan produksi akibat pemanfaatan kredit sebesar 24,50 persen. Berbeda dengan temuan Asih et al. (2008) yang menyatakan peningkatan produksi mencapai 94 persen. Besarnya pengaruh pemanfaatan kredit terhadap produksi usahatani menunjukkan bahwa pengaruh kredit bergantung pada besarnya pemanfaatan kredit untuk usahatani. Berdasarkan uraian di atas, maka tujuan penelitian ini adalah (1) menganalisis pemanfaatan KKPE pada usaha ayam ras pedaging dan (2) menganalisis pengaruh KKPE terhadap produksi ayam ras pedaging.

\section{METODE}

\section{METODE PENGUMPULAN DATA}

Penelitian ini berbasis data primer yang diperoleh melalui wawancara terhadap 85 peternak ayam ras pedaging penerima KKPE di Kabupaten Padang Pariaman. Data primer penelitian ini didukung dengan data sekunder dari bank pelaksana KKPE di Sumatera Barat, Kementerian Pertanian RI, Badan Pusat Statistik, instansi terkait dan literatur lainnya seperti buku, jurnal dan penelitian terdahulu.

\section{METODE PENENTUAN SAMPEL}

Penentuan sampel dilakukan menggunakan metode simple random sampling dengan pertimbangan jumlah kredit yang diterima oleh peternak bersifat homogen, sehingga diambil 85 peternak (80 persen) dari 108 peternak dengan pertimbangan jumlah tersebut mampu mewakili tujuan penelitian. Penentuan kerangka sampling menggunakan bantuan tabel acak sederhana. 


\section{METODE ANALISIS DATA}

\section{Analisis Pemanfaatan KKPE pada Usaha Ayam Ras Pedaging}

Analisis pemanfaatan KKPE pada usaha ayam ras pedaging dilakukan dengan analisis tabulasi yang memuat persentase pemanfaatan kredit. Pemanfaatan kredit selain untuk ayam ras pedaging menunjuk-kan adanya fungibility credit. Menurut Hussain dan Thapa (2015), fungibility credit ditentukan dengan rumus berikut:

$\mathrm{FC}=\frac{\mathrm{C}_{\mathrm{f}}}{\mathrm{C}_{\mathrm{t}}} \times 100 \%$

Dimana, FC yaitu fungibility credit (persen), $\mathrm{C}_{f}$ yaitu jumlah pemanfaatan KKPE selain untuk ayam ras pedaging (Rp) dan $\mathrm{C}_{t}$ yaitu jumlah kredit yang diterima peternak (Rp). Fungibility credit peternak dikategorikan menjadi fungibility credit rendah dan fungibility credit tinggi dengan persentase fungibility credit sebagai indikator fungibility credit ditentukan dengan rumus berikut :

$\overline{\mathrm{FC}}=\sum \mathrm{FC} / \mathrm{n}$

Dimana, FC yaitu fungibility credit rata-rata peternak (persen), $\sum F C$ yaitu jumlah fungibility credit dan n yaitu jumlah sampel. Fungibility credit rendah jika fungibility peternak lebih kecil dari pada fungibility credit rata-rata, sedangkan fungibility credit tinggi jika fungibility peternak lebih besar dari pada fungibility credit rata-rata.

\section{Analisis Pengaruh KKPE terhadap Produksi Ayam Ras Pedaging}

Pengaruh KKPE terhadap produksi diantaranya dianalisis dengan analisis fungsi produksi ayam ras pedaging menggunakan fungsi produksi Cobb Douglas. Variabel independen fungsi produksi ayam ras pedaging yaitu jumlah DOC $\left(\mathrm{X}_{1}\right)$, pakan $\left(\mathrm{X}_{2}\right)$, vitamin DOC $\left(X_{3}\right)$, vitamin ayam $\left(X_{4}\right)$, vaksin $\left(X_{5}\right)$, obat $\left(X_{6}\right)$ dan tenaga kerja $\left(X_{7}\right)$. Penggunaan variabel independen $X_{1}-X_{7}$ dikarenakan input tersebut merupakan input ayam ras pedaging yang jumlah penggunaannya berpengaruh terhadap jumlah produksi daging ayam dan penggunaannya meningkat dengan memanfaatkan kredit.

Analisis fungsi produksi ayam ras pedaging dilakukan menggunakan data penggunaan input sebelum kredit untuk melihat hubungan masing-masing penggunaan input terhadap produksi sebelum kredit. Analisis fungsi produksi dilakukan mengunakan model berikut :
$\ln Y=\alpha+\beta_{1} \ln X_{1}+\beta_{2} \ln X_{2}+\beta_{3} \ln X_{3}+\beta_{4} \ln X_{4}+\beta_{5} \ln X_{5}+$ $\beta_{6} \ln X_{6}+\beta_{7} \ln X_{7}+\mathrm{e}$.

${ }^{*} \alpha, \beta_{1}, \beta_{2}, \beta_{3}, \beta_{4}, \beta_{5}, \beta_{6,}, \beta_{7}>0,<0$

Dimana $Y=$ jumlah produksi daging ayam ras pedaging sebelum kredit $(\mathrm{kg}), \mathrm{a}=$ intercept, $\beta \mathrm{i}=$ koefisien parameter penduga $(\mathrm{i}=$ $1,2,3,4,5,6,7), X_{1}=$ jumlah DOC (ekor), $X_{2}=$ jumlah pakan $(\mathrm{kg}), X_{3}=$ jumlah vitamin DOC (gr), $X_{4}=$ jumlah vitamin ayam $(\mathrm{ml}), X_{5}=$ jumlah vaksin (ml), $X_{6}=$ jumlah obat (gr), $X_{7}=$ jam kerja tenaga kerja $(\mathrm{HOK})$, dan $\mathrm{e}=$ error .

Hasil regresi menunjukkan respon masing-masing input jika dilakukan penambahan input. Input dengan pengaruh signifikan menunjukkan penggunaan input yang sesuai anjuran, sedangkan input yang berpengaruh negatif maupun tidak signifikan terhadap produksi diduga penggunaannya tidak sesuai anjuran. Dengan mengetahui pengaruh masing-masing input terhadap produksi, koefisien persamaan (3) digunakan untuk menduga produksi pada kondisi penggunaan input sebelum kredit penggunaan input sesudah pemanfaatan kredit dengan persamaan berikut :

$$
\begin{aligned}
\mathrm{Y}= & \alpha+\beta_{1 \mathrm{i}} \bar{X}_{1 i}+\beta_{2 \mathrm{i}} \bar{X}_{2 i}+\beta_{3 \mathrm{i}} \bar{X}_{3 i}+\beta_{4 \mathrm{i}} \bar{X}_{4 i}+\beta_{5 \mathrm{i}} \bar{X}_{5 i}+ \\
& \beta_{6 \mathrm{X}} \bar{X}_{6 i}+\beta_{7 \mathrm{i}} \bar{X}_{7 i}+\mathrm{e} \ldots \ldots \ldots \ldots \ldots \ldots \ldots \ldots \ldots .(4)
\end{aligned}
$$

Dimana :

$\widehat{Y}=$ dugaan produksi $(\mathrm{kg})$

$\mathrm{Bi}=$ koefisien parameter penduga $\mathrm{X}_{1}-\mathrm{X}_{7}$ 
$\overline{X_{1}}=$ rata-rata penggunaan bibit, $\mathrm{a}=$ sebelum kredit, b = sesudah kredit (ekor/siklus)

$\overline{X_{2}}=$ rata-rata jumlah pakan ternak, $\mathrm{a}=$ sebelum kredit, $b=$ sesudah kredit (kg/siklus)

$\overline{X_{3}}=$ rata-rata jumlah vitamin DOC, a $=$ sebelum kredit, $b=$ sesudah kredit (gr/siklus)

$\overline{X_{4}}=$ rata-rata jumlah vitamin ayam, $\mathrm{a}=$ sebelum kredit, $b=$ sesudah kredit (ml/siklus)

$\overline{X_{5}}=$ rata-rata jumlah vaksin, $\mathrm{a}=$ sebelum kredit, $\mathrm{b}=$ sesudah kredit (ml/siklus)

$\overline{X_{6}}=$ rata-rata jumlah obat, $\mathrm{a}=$ sebelum kredit, b = sesudah kredit (gr/siklus)

$\overline{X_{7}}=$ rata-rata jumlah jam kerja tenaga kerja, $\mathrm{a}=$ sebelum kredit, $\mathrm{b}=$ sesudah kredit (HOK/siklus)

$e=$ error

\section{Uji Asumsi Klasik Fungsi Produksi Ayam Ras Pedaging}

Model fungsi produksi ayam ras pedaging yang digunakan telah memenuhi kriteria BLUE (Best, Linear, Unbiased and Estimated) dengan uji asumsi klasik menggunakan SPSS versi 23. Hasil uji normalitas menggunakan uji Kolmogorov Smirnov menunjukkan nilai signifikansi 0,200 > 0,05 $(\alpha=0,05)$ artinya asumsi normalitas terpenuhi. Uji heteroskedastisitas pada fungsi menunjukkan tidak adanya pelanggaran. Hasil uji Park menunjukkan nilai t-hitung masing-masing variabel tidak signifikan, sehingga disimpulkan tidak terjadi heteroskedastisitas. Hasil uji autokorelasi menggunakan uji Durbin Watson menghasilkan nilai d sebesar 2,020 yang menunjukkan tidak terjadinya autokorelasi dengan kriteria pengambilan keputusan dU $<$ d $<$ dW yaitu 0,801 < 0,202 < 2,199 yang artinya tidak terjadi autokorelasi. Selain itu, hasil uji multikolinearitas juga menunjukkan tidak terjadi pelanggaran multikolinearitas karena nilai VIF masingmasing variabel independen $<10$.
Tabel 2. Hasil Uji Multikolinearitas Fungsi Produksi Ayam Ras Pedaging

\begin{tabular}{lc}
\hline \multicolumn{1}{c}{ Variabel independen } & VIF \\
\hline DOC & 7,301 \\
Pakan & 2,331 \\
Vitamin DOC & 2,468 \\
Vitamin ayam & 1,071 \\
Vaksin & 1,023 \\
Obat & 5,972 \\
TK & 1,049 \\
\hline
\end{tabular}

Model dikatakan baik karena nilai Adjusted $R$ Square $\left(\mathrm{R}^{2}{ }_{\mathrm{adj}}\right)$ dari hasil regresi menggunakan SPSS versi 23 menunjukkan nilai sebesar 0,898 artinya 89,80 persen variasi perubahan produksi dipengaruhi oleh variasi independen pada model. Uji $F$ atau uji simultan juga menunjukkan nilai F-hitung sebesar 168,14 yang lebih besar daripada Ftabel yaitu 2.13, sehingga tolak $\mathrm{H}_{0}$ : variabel independen input secara simultan atau bersama-sama berpengaruh terhadap variabel dependen produksi.

Uji $\mathrm{t}$ yang dilakukan untuk mengetahui pengaruh variabel independen input terhadap variabel dependen produksi menunjukkan bahwa variabel independen vaksin berpengaruh signifikan terhadap produksi pada taraf 1 persen, variabel vitamin DOC dan obat berpengaruh signifikan terhadap produksi pada taraf 5 persen, dan vitamin ayam berpengaruh signifikan terhadap produksi pada taraf 10 persen.

\section{HASIL DAN PEMBAHASAN}

\section{PEMANFAATAN KKPE PADA USAHA AYAM RAS PEDAGING}

Kredit sebagai sumber modal dalam sektor pertanian pemanfaatannya ditujukan untuk kegiatan produktif diantaranya untuk pengadaan sarana dan prasarana produksi yang berperan dalam peningkatan produksi. Rata-rata KKPE yang diterima peternak sebesar Rp. 57.116.000/peternak, seperti ditunjukkan pada Tabel 3. Jumlah kredit menunjukan jumlah yang relatif rendah dibandingkan plafon kredit per peternak yaitu Rp. 100.000.000. Meskipun jumlah KKPE 
yang diterima peternak relatif rendah, namun kredit mampu membiayai usaha ayam ras pedaging dan kredit digunakan dengan optimal oleh peternak.

Tabel 3. Rata-rata Pemanfaatan KKPE pada Usaha Ayam Ras Pedaging

\begin{tabular}{lrr}
\hline $\begin{array}{c}\text { Pemanfaatan } \\
\text { KKPE }\end{array}$ & $\begin{array}{c}\text { Jumlah } \\
\text { kredit (Rp) }\end{array}$ & $\begin{array}{c}\text { Persentase } \\
\text { pemanfaatan } \\
\text { KKPE (\%) }\end{array}$ \\
\hline $\begin{array}{l}\text { Usaha ayam } \\
\text { ras pedaging }\end{array}$ & 53.969 .000 & 94,49 \\
$\begin{array}{l}\text { Selain usaha } \\
\text { ayam ras } \\
\text { pedaging }\end{array}$ & 3.147 .000 & 5,51 \\
Jumlah & 57.116 .000 & 100,00 \\
\hline
\end{tabular}

Berdasarkan Tabel 3, dari rata-rata KKPE yang diterima peternak sebesar Rp. 57.116.000, kredit dimanfaatkan peternak untuk usaha ayam ras pedaging sebesar 94,49 persen, sedangkan sebesar 5,51 persen dimanfaatkan untuk kebutuhan selain usaha ayam ras pedaging. Kredit yang dimanfaatkan untuk ayam ras pedaging digunakan untuk investasi dan modal kerja (Tabel 4), sedangkan pemanfaatan KKPE selain untuk ayam ras pedaging dimanfaatkan untuk usaha pangan, hortikultura, perikanan dan dimanfaatkan untuk kebutuhan konsumsi, pendidikan dan kesehatan (Tabel 6).

Tabel 4. Rata-rata Pemanfaatan KKPE pada Usaha Ayam Ras Pedaging

\begin{tabular}{lrr}
\hline $\begin{array}{c}\text { Pemanfaatan } \\
\text { KKPE }\end{array}$ & $\begin{array}{c}\text { Rata-rata } \\
\text { pemanfaatan } \\
\text { KKPE (Rp) }\end{array}$ & $\begin{array}{c}\text { Persentase } \\
\text { pemanfaatan } \\
\text { KKPE (persen) }\end{array}$ \\
\hline Modal kerja & & \\
\hline DOC & 20.079 .000 & 35,15 \\
Pakan & 24.511 .000 & 42,91 \\
Obat & 416.000 & 0,73 \\
Vitamin & 955.100 & 1,67 \\
Vaksin & 834.000 & 1,46 \\
Gas/briket & 186.800 & 0,33 \\
Listrik & 376.000 & 0,66 \\
Transportasi & 315.000 & 0,55 \\
Tenaga kerja & 2.885 .000 & 5,05 \\
\hline Investasi & & \\
\hline Tempat pakan & 865.000 & 1,51 \\
Mesin cuci & 1.050 .000 & 1,84 \\
kandang & & \\
Pemanas DOC & 1.195 .000 & 2,09 \\
Becak motor & 3.450 .000 & 6,04 \\
Total & 53.969 .000 & 100,00 \\
\hline
\end{tabular}

Pemanfaatan KKPE untuk modal kerja dimanfaatkan dengan persentase yang lebih besar yaitu 89,56 persen yaitu Rp. 48.229.557, sedangkan pemanfaatan KKPE untuk investasi usaha dimanfaatkan sebesar 10,44 persen yaitu Rp. 4.816.540. Pemanfaatan KKPE pada Tabel 4 menunjukkan bahwa pemanfaatan KKPE untuk modal kerja digunakan dengan persentase yang bervariasi untuk masingmasing modal kerja bergantung pada besarnya biaya produksi yang dibutuhkan untuk pengadaan masing-masing modal kerja.

Berdasarkan Tabel 4, pemanfaatan KKPE terbesar digunakan untuk pengadaan pakan yaitu 42,91 persen. Selain itu, pemanfaatan KKPE dalam dengan proporsi besar dimanfaatkan untuk pengadaan DOC yaitu 35,15 persen, sedangkan pemanfaatan KKPE untuk modal kerja selain DOC dan pakan, hanya dimanfaatkan dengan persentase $<10$ persen. Besarnya pemanfaatan KKPE untuk modal kerja dengan rata-rata pemanfaatan sebesar 89,56 persen dikarenakan besarnya biaya yang dikeluarkan untuk pengadaan modal kerja usaha ayam ras pedaging. Hal ini dinyatakan oleh Daryanto (2009), bahwa penggunaan biaya produksi pada usaha ayam ras pedaging didominasi oleh biaya DOC dan pakan, sedangkan modal kerja lainnya hanya sebagian kecil dari biaya produksi.

Pemanfaatan KKPE selain digunakan untuk modal kerja juga digunakan untuk investasi berupa pembelian tempat pakan, mesin cuci kandang, pemanas DOC, serta melakukan pembuatan becak motor dengan biaya investasi 1,51 - 6,04 persen. Investasi dilakukan karena adanya penambahan jumlah ternak yang dibudidayakan, sehingga menambah peralatan usaha seperti tempat pakan. Selain itu, investasi juga dilakukan karena kondisi peralatan yang rusak dan harus diganti agar pemeliharaan ternak tidak terganggu.

Pemanfaatan KKPE selain untuk ayam ras pedaging seperti pada Tabel 3 menunjukkan adanya fungibility credit. Berdasarkan jumlah pemanfaatan KKPE selain untuk ayam ras pedaging, dihasilkan 
indikator fungibility credit sebesar 5,51 persen. Fungibility credit pada usaha ayam ras pedaging menunjukkan adanya variasi. Dari 27 peternak yang memanfaatkan kredit selain untuk usaha ayam ras pedaging, memanfaatkan kredit berkisar antara 0,86 persen hingga 11,97 persen. Pemanfaatan KKPE untuk kebutuhan selain usaha ayam ras pedaging dikategorikan dengan indikator fungibility credit sebesar 5,51 persen, maka fungibility credit usaha ayam ras pedaging terbagi menjadi fungibility credit rendah dan fungibility credit tinggi seperti pada Tabel 5 .

Tabel 5. Fungibility Credit Usaha Ayam Ras Pedaging

\begin{tabular}{lcc}
\hline $\begin{array}{l}\text { Fungibility credit } \\
(\boldsymbol{C} \boldsymbol{f}>\mathbf{5 . 5 1} \text { persen) }\end{array}$ & $\begin{array}{c}\text { Fungibility } \\
\text { credit (\%) }\end{array}$ & $\begin{array}{c}\text { Jumlah } \\
\text { peternak } \\
\text { (orang) }\end{array}$ \\
\hline $\begin{array}{l}\text { Fungibility credit } \\
\text { rendah }\end{array}$ & $0,86-5,50$ & 14 \\
$\begin{array}{l}\text { Fungibility credit } \\
\text { tinggi }\end{array}$ & $5,52-11,97$ & 13 \\
Jumlah & & 27 \\
\hline
\end{tabular}

Berdasarkan Tabel 5, sebaran peternak dengan fungibility credit tinggi dan rendah memiliki proporsi yang hampir sama. Peternak dengan fungibility credit rendah memanfaatkan KKPE dengan persentase pemanfaatan KKPE untuk selain usaha ayam ras pedaging sebanyak $0,86-5,50$ persen dari jumlah kredit yang diterima, dan peternak dengan fungibility credit tinggi memanfaatkan KKPE untuk selain usaha ayam ras pedaging mencapai 11,97 persen. KKPE yang dimanfaatkan untuk selain usaha ayam ras pedaging diantaranya digunakan untuk usaha produktif usaha pangan, hortikultura, dan perikanan, dan digunakan untuk konsumsi seperti pada Tabel 6.

Pemanfaatan KKPE untuk kebutuhan selain usaha ayam ras pedaging menunjukkan bahwa pemanfaatan KKPE untuk kebutuhan produktif lebih besar yaitu 3.38 persen dibandingkan pemanfaatan KKPE untuk konsumtif sebesar 2.13 persen. Pemanfaatan kredit untuk usaha selain ayam ras pedaging, dilakukan karena kebutuhan terhadap usaha ayam ras pedaging telah terpenuhi, sehingga peternak memanfaatkan kredit untuk usaha yang dianggap produktif dan meningkatkan pendapatan. Selain itu, alasan yang mendorong pemanfaatan KKPE untuk konsumsi dikarenakan adanya kebutuhan peternak yang harus dipenuhi seperti kebutuhan keluarga berupa transportasi, komunikasi dan perbaikan kendaraan; pendidikan dan kesehatan. Sedangkan usaha sampingan peternak pada umumnya memiliki musim tanam yang lebih lama yaitu 3-5 bulan dibandingkan usaha ayam ras pedaging yang hanya 28-37 hari, dan kondisinya usaha peternak belum panen, maka peternak menggunakan dana kredit untuk memenuhi kebutuhan konsumtif.

Tabel 6. Rata-rata Pemanfaatan KKPE Selain untuk Usaha Ayam Ras Pedaging

\begin{tabular}{ccc}
\hline $\begin{array}{c}\text { Pemanfaatan } \\
\text { KKPE }\end{array}$ & $\begin{array}{c}\text { Rata-rata } \\
\text { pemanfaatan } \\
\text { KKPE (Rp) }\end{array}$ & $\begin{array}{c}\text { Persentase } \\
\text { pemanfaatan } \\
\text { KKPE (\%) }\end{array}$ \\
\hline Produktif & & \\
\hline Bayam & 366.000 & 0,69 \\
Kangkung & 190.500 & 0,33 \\
Jagung & 365.000 & 0,74 \\
Ikan nila & 926.500 & 1,62 \\
\hline Konsumtif & & \\
\hline Konsumsi & 276.500 & 0,38 \\
Pendidikan & 435.000 & 0,72 \\
Kesehatan & 589.000 & 1,03 \\
\hline
\end{tabular}

Berbeda dengan fungibility credit usahatani sapi pada penelitian Sinaga et al. (2013) yang menyatakan bahwa pemanfaatan kredit untuk usaha selain usahatani sapi dikarenakan jumlah kredit yang diterima peternak relatif rendah. Jumlah kredit hanya mampu menambah 2-3 ekor sapi sehingga peternak memilih menggunakannya untuk usaha produktif lainnya yang mampu meningkatkan pendapatan peternak dibandingkan memanfaatkan kredit untuk usahatani sapi. Pernyataan tersebut juga diungkapkan Iski et al. (2015) dan Dewi et al. (2015), bahwa peternak melakukan pemanfaatan kredit untuk usaha selain usahatani yang dibiayai kredit dikarenakan usaha tersebut juga merupakan sumber pendapatan keluarga. Penelitian Kuwornu et al. (2012); Oboh dan Ekpebu (2011), menyatakan bahwa pemanfaatan kredit selain untuk usahatani disebabkan oleh 
lemahnya kondisi ekonomi dan besarnya tanggungan keluarga, sehingga peternak menggunakan kredit untuk kebutuhan seharihari.

Fungibility credit sebesar 5,51 persen tergolong relatif rendah dibandingkan hasil penelitian sebelumnya. Tingkat fungibility credit di Indonesia berdasarkan hasil penelitian menunjukkan fungibility credit terendah yaitu 23,60 persen pada penelitian Dewi et al. (2016) dan fungibility credit tertinggi ditemukan pada penelitian Iski et al. (2015) dengan fungibility credit mencapai 79,10 persen. Begitu juga dengan fungibility credit usahatani di luar negeri yang menunjukkan tingkat fungibility credit relatif tinggi. Kuwornu et al. (2013) menyatakan fungibility credit usaha ternak sebesar 27,57 persen. Bahkan hasil studi Adebayo dan Adeola (2008) menunjukkan fungibility credit mencapai 67 persen.

\section{FAKTOR-FAKTOR YANG MEMENGARUHI PRODUKSI AYAM RAS PEDAGING}

Pengaruh penggunaan input sebelum kredit terhadap produksi ayam ras pedaging menggunakan fungsi produksi ayam ras pedaging telah memenuhi asumsi BLUE di antaranya data terdistribusi normal, tidak adanya korelasi antar variabel independen, tidak adanya pelanggaran heteroskedastisitas dan autokorelasi. Nilai koefisien determinasi terkoreksi (Adj $\mathrm{R}^{2}$ ) pada modal yang dibentuk yaitu sebesar 0.898 artinya 89,80 persen variabel dependen produksi dipengaruhi oleh variabel independen pada model. Analisis regresi untuk melihat pengaruh penggunaan masing-masing input fungsi produksi ayam ras pedaging menunjukkan output pada Tabel 7.

Pengaruh penggunaan input terhadap produksi ayam ras pedaging dilihat dari respon penggunaan input. Berdasarkan Tabel 5, input yang memiliki respon paling tinggi yaitu pakan. Nilai koefisien input pakan sebesar 0,452 menunjukkan elastisitas produksi dimana respon perubahan produksi dengan peningkatan penggunaan input pakan sebanyak 1 persen adalah sebesar 0,452 persen. Tingginya respon variabel pakan dikarenakan input pakan merupakan input utama yang menunjang pertumbuhan ternak, sehingga penggunaannya berpengaruh besar terhadap produksi. Namun hasil analisis regresi pada Tabel 7 menunjukkan penggunaan input pakan tidak berpengaruh signifikan terhadap produksi. Penelusuran terhadap data lapangan yaitu penggunaan input sebelum kredit (Tabel 8) menunjukkan bahwa penggunaan input pakan tidak sesuai anjuran. Penggunaan input pakan hanya $0.79 \mathrm{~kg} /$ ekor/siklus, padahal ayam ras pedaging membutuhkan pakan $0.99 \mathrm{~kg} /$ ekor/siklus (Suprijatna et al. 2005). Respon yang tinggi terhadap input pakan juga ditunjukkan pada studi Vinanda et al. (2015). Pakan memiliki respon yang tinggi terhadap produksi sekaligus berpengaruh signifikan terhadap produksi ayam ras pedaging karena penggunaan input pakan yang mencukupi kebutuhan ternak yaitu rata-rata $1.02 \mathrm{~kg} /$ ekor/siklus.

Pengaruh signifikan penggunaan input terhadap produksi pada Tabel 7 ditunjukkan

Tabel 7. Hasil Pendugaan Parameter Model Fungsi Produksi Ayam Ras Pedaging

\begin{tabular}{lccc}
\hline \multicolumn{1}{c}{ Variabel } & Koefisien & t-hitung & Sig \\
\hline Konstanta & 1,134 & 9,076 & 0,000 \\
DOC $\left(X_{1}\right)$ & $-0,056$ & 0,276 & 0,860 \\
Pakan $\left(X_{2}\right)$ & 0,452 & 0,903 & 0,369 \\
Vitamin DOC $\left(X_{3}\right)$ & $0,122^{* *}$ & 2,068 & 0,043 \\
Vitamin ayam $\left(X_{4}\right)$ & $0,231^{*}$ & 1,775 & 0,072 \\
Vaksin $\left(X_{5}\right)$ & $0,303^{* * *}$ & 6,553 & 0,003 \\
Obat $\left(X_{6}\right)$ & $0,150^{* *}$ & 7,486 & 0,032 \\
Tenaga kerja $\left(X_{7}\right)$ & 0,055 & $-1,380$ & 0,171 \\
\hline
\end{tabular}

Keterangan : ${ }^{* * *}=$ berpengaruh signifikan pada taraf 1 persen

** = berpengaruh signifikan pada taraf 5 persen

* = berpengaruh signifikan pada taraf 10 persen 
pada penggunaan input vitamin, vaksin dan obat. Besarnya pengaruh input vitamin, vaksin dan obat dikarenakan input tersebut merupakan input penunjang pertumbuhan ternak. Menurut Tamalluddin (2012), besarnya pengaruh input vitamin terhadap produksi dikarenakan input tersebut mengandung nutrisi untuk meningkatkan pertumbuhan dan perkembangan ternak melalui pembentukan sistem imun pada DOC dan menjaga daya tahan tubuh ternak terhadap kondisi lingkungan. Di samping itu, obat dan vaksin berpengaruh positif dan signifikan karena obat dan vaksin berfungsi sebagai pencegah agar ternak tidak terserang penyakit yang dapat menyebabkan kematian pada ternak sehingga memengaruhi produksi. Hal ini juga diungkapkan Ali dan Riaz (2014) yang menyatakan bahwa pemberian vaksin dan obat pada ternak akan meningkatkan kekebalan tubuh ternak sehingga tidak mudah terserang penyakit.

\section{PENGARUH KKPE TERHADAP PRODUKSI AYAM RAS PEDAGING}

Pengaruh pemanfaatan KKPE terhadap produksi ayam ras pedaging dilihat melalui peningkatan penggunaan input. Pemanfaatan KKPE dalam proporsi mencapai 9,49 persen untuk usaha ayam ras pedaging yang pemanfaatan digunakan untuk pengadaan input, menunjukkan peningkatan penggunaan input pada usaha ayam ras pedaging seperti ditunjukkan pada Tabel 8 .

Tabel 8 menunjukkan peningkatan penggunaan input ayam ras pedaging tidak hanya terjadi pada input yang memiliki respon tinggi saja namun terjadi peningkatan pada semua input variabel diantaranya DOC, pakan, vitamin DOC, vitamin ayam, vaksin, obat dan tenaga kerja. Peningkatan penggunaan input yang tinggi ditunjukkan pada vitamin ayam, vitamin DOC, dan obat. Peningkatan penggunaan input diantaranya disebabkan oleh peningkatan jumlah DOC yang dibudidayakan.

Pemanfaatan KKPE yang meningkatkan penggunaan input seperti pada Tabel 8 berpengaruh terhadap produksi ayam ras pedaging. Jumlah produksi ternak sebelum kredit berdasarkan perhitungan dugaan produksi menggunakan persamaan (4) menunjukkan bahwa produksi ayam ras pedaging sebelum kredit sebanyak 2.151,86 kg. Oleh karena adanya peningkatan penggunaan input yang ditunjukkan pada Tabel 6,786 jumlah produksi sesudah kredit mengalami peningkatan. Hasil dugaan produksi sesudah kredit menunjukkan bahwa produksi ternak meningkat 47,52 persen menjadi $3.174,53 \mathrm{~kg}$. Rata-rata ternak yang dipanen sebelum kredit hanya sebanyak 2.102 ekor dengan rata-rata bobot ternak $0,95 \mathrm{~kg} /$ ekor sedangkan ratarata panen sesudah kredit berjumlah 3.253 ekor dengan bobot rata-rata $1,29 \mathrm{~kg} /$ ekor.

Tingginya pengaruh pemanfaatan KKPE terhadap produksi dikarenakan penggunaan masing-masing input meningkat. Selain itu, input yang responsif dan berpengaruh signifikan terhadap produksi diantaranya pakan, vitamin, vaksin dan obat digunakan dalam jumlah besar sehingga produksi yang dihasilkan tinggi. Selain itu, peningkatan produksi ternak dikarenakan penggunaan input yang lebih baik sehingga pertumbuhan ternak lebih baik dan meningkatkan produksi.

Tabel 8. Jumlah Penggunaan Input dan Produksi Ayam Ras Pedaging Sebelum dan Sesudah Kredit per Siklus

\begin{tabular}{lcccc}
\hline \multirow{2}{*}{ Input } & \multicolumn{2}{c}{ Rata-rata penggunaan input } & \multicolumn{2}{c}{$\begin{array}{c}\text { Persentase } \\
\text { peningkatan (\%) }\end{array}$} \\
\cline { 2 - 5 } & Satuan & Sebelum kredit & Sesudah kredit & 32,85 \\
Pakan & ekor & $2.462,00$ & $3.404,00$ & 40,38 \\
Vitamin DOC & $\mathrm{kg}$ & $3.114,65$ & $4.372,38$ & 33,16 \\
Vitamin ayam & $\mathrm{gr}$ & $1.864,12$ & $2.282,35$ & 57,90 \\
Vaksin & $\mathrm{ml}$ & $1.682,35$ & $2.656,47$ & 52,70 \\
Obat & $\mathrm{ml}$ & 1.284 .50 & 1.961 .50 & 45,13 \\
Tenaga kerja & $\mathrm{gr}$ & $1.646,39$ & $2.389,45$ & 19,25 \\
\hline
\end{tabular}


Penggunaan pakan rata-rata per ekor ternak meningkat dari penggunaan sebelumnya. Penggunaan pakan sebelum kredit hanya sebesar $0,79 \mathrm{~kg} /$ ekor mengalami peningkatan menjadi $0,94 \mathrm{~kg} /$ ekor yang mendekati kebutuhan pakan hingga panen sebesar 0,99 $\mathrm{kg}$ /ekor. Penggunaan vitamin dan DOC juga menunjukkan pemanfaatan yang lebih baik. Penggunaan vitamin DOC sebelum kredit meningkat dari rata-rata penggunaan sebelum kredit sebanyak $0,62 \mathrm{ml} /$ ternak meningkat menjadi $0,68 \mathrm{ml} /$ ternak. Selain itu, penambahan DOC disertai dengan perluasan penggunaan kandang yang menyebabkan kepadatan ternak berkurang menjadi 8 ekor $/ \mathrm{m}^{2}$ dari sebelum kredit dengan kepadatan ternak 12 ekor $/ \mathrm{m}^{2}$. Pengurangan kepadatan kandang akan mengurangi risiko stres, dan persaingan pakan antar ternak.

Peningkatan produksi akibat penggunaan kredit untuk peningkatan penggunaan input juga ditunjukkan pada studi Bashir et al. (2010), bahwa peningkatan produksi setelah kredit sebesar 24,50 persen. Bahkan, hasil studi Asih et al. (2008) menyatakan bahwa kredit mampu meningkatkan produksi mencapai 94 persen karena kredit digunakan untuk investasi yang menunjang jumlah ikan yang dapat ditangkap dengan melakukan investasi mesin dan alat tangkap. Selain itu, Awotide et al. (2015) menyatakan bahwa penggunaan kredit menyebabkan peningkatan penggunaan input, sehingga produksi petani pengguna kredit 23,32 persen lebih tinggi dibandingkan dengan petani yang tidak menggunakan kredit.

Besarnya produksi petani pengguna kredit dikarenakan tingginya pemanfaatan kredit untuk usahatani yang dibiayai kredit, diantaranya pada studi Asih et al. (2008) yang menyatakan pemanfaatan kredit sebesar 90 persen untuk investasi alat tangkap ikan, dan studi Awotide et al. (2015) yang menyatakan pemanfaatan sebesar 69,98 persen. Berbeda dengan temuan Dewi et al. (2015) yang menyatakan bahwa pemanfaatan kredit meningkatkan produksi hanya sebesar 18,93 persen. Rendahnya peningkatan produksi dikarenakan pemanfaatan kredit yang tidak sepenuh- nya untuk usahatani padi, yaitu hanya 46,90 persen. Hal ini menunjukan bahwa semakin tinggi pemanfaatan kredit untuk usaha yang dibiayai kredit maka akan semakin tinggi peningkatan produksi.

\section{KESIMPULAN DAN SARAN}

\section{KESIMPULAN}

1. Pemanfaatan KKPE pada usaha ayam ras pedaging tidak sepenuhnya dimanfaatkan untuk usaha ayam ras pedaging. Rata-rata pemanfaatan untuk usaha ayam ras pedaging sebesar 94,49 persen sehingga terdapat fungibility credit sebesar 5,51 persen (rendah).

2. Pemanfaatan KKPE dengan proporsi besar untuk peningkatan penggunaan input ayam ras pedaging mampu meningkatkan produksi ayam ras pedaging sebesar 47,52 persen dari produksi sebelum kredit yaitu $2.151,86 \mathrm{~kg} /$ siklus menjadi $3.174,53 \mathrm{~kg} /$ siklus sesudah kredit.

\section{SARAN}

1. Tingginya pengaruh KKPE terhadap produksi ayam ras pedaging oleh karena pemanfaatan kredit yang relatif tinggi, diharapkan penggunaan KKPE dioptimalkan untuk usaha yang dibiayai kredit agar peningkatan produksi tercapai dan mampu memenuhi kebutuhan konsumsi daging nasional.

2. Untuk mendukung pencapaian dampak tersebut, perlu dilaksanakan kontrol dan peninjauan langsung ke lapangan untuk mengantisipasi penyalahgunaan kredit oleh peternak untuk kebutuhan selain usaha yang dibiayai kredit.

\section{DAFTAR PUSTAKA}

Ali S, Riaz B. 2014. Estimation of technical efficiency open shed broiler farmers in Punjab Pakistan: a stochastic frontier analysis. Journal of Economics and Sustainable Development. 5(7): 79-89. 
Asih DN, Harianto, Kusnadi N. 2008. Dampak kredit terhadap usaha perikanan dan ekonomi rumah tangga nelayan tradisional di Kabupaten Tojo Una-Una Provinsi Sulawesi Selatan. Forum Pascasarjana. 31(4): 269-278.

Awotide BA, Abdoulaye T, Alene A, Manyong VM. 2015. Impact of access to credit on agricultural productivity: evidence from smallholder Cassava farmers in Nigeria International Conference of Agricultural Economists. 1-34.

Aziz A, Wicaksono E. 2016. Analisis skema alternatif kredit program untuk usaha mikro, kecil dan menengah. Jurnal Ekonomi dan Kebijakan Publik. 7(2): 143157.

Bahari DI, Fanani, Z, Nugroho, B.A. 2012. Analisis struktur biaya dan perbedaan pendapatan usaha ayam ras pedaging pada pola dan skala usaha ternak yang berbeda di Kota Kendari Provinsi Sulawesi Tenggara. Jurnal Ternak Tropika. 13(1): 35-46.

Bashir MK, Sarfraz H, Yasir M. 2010. Impact of agricultural credit on productivity of wheat crop: evidence from Lahore, Punjab, Pakistan. Pakistan Journal Agribusiness and Social. 47(4): 405-409.

[BPS] Badan Pusat Statistik. 2018. Statistik Peternakan dan Kesehatan Hewan 2018. Badan Pusat Statistik. Jakarta.

[BPS] Badan Pusat Statistik. 2019. Sumatera Barat dalam angka tahun 2018. Badan Pusat Statistik. Padang.

Cheng E, Rahman MW, Luo J. 2011. Policies and performances of agricultural rural credit in Bangladesh: What is the influence of agricultural production?. African Journal of Agricultural Research. 6(31): 6440 - 6452.

Dahri, Hutagaol P, Siregar H, Simatupang P. 2015. Dampak KKPE dalam pengembalian usaha ternak sapi di Jawa Tengah. Jurnal Manajemen Agribisnis. 12 (2): 115-125.
Daryanto A. 2009. Dinamika daya saing industri peternakan. Bogor : IPB Press.

Derosari BB, Sinaga BM, Kusnadi N. 2014. The impact of credit and capital supports on economic behavior of farm households: a household economic approach. International Journal of Food and Agricultural Economic. 2(3): 81-90.

Dewi IS, Rachmina D, Trinaprilla N. 2015. Peranan KKPE dalam peningkatan produksi dan keuntungan usahatani padi di Kabupaten Kampar Riau. Jurnal Dinamika Pertanian. 30(2): 163-170.

Dharmawan SS, Karyani T. 2018. Dampak kredit terhadap pendapatan usahatani kopi arabika. Jurnal Agribisnis Terpadu. 11(1): 80-90.

Hussain A, Thapa GB. 2015. Fungibility of smallholder agricultural credit empirical evidence from Pakistan. European Journal of Development Research. 1-21.

Ijioma JC, Charles KO. 2015. Agricultural credit sources and determinants of credit acquisition by farmers in Idemili local government area of Anambra State. Journal of Agricultural Science and Technology. 5(2015): 34-43.

Iski N, Kusnadi N, Harianto. 2016. Pengaruh kredit terhadap pendapatan petani Kopi Arabika di Kabupaten Aceh Tengah Provinsi Aceh. Jurnal Manajemen Agribisnis. 13 (2): 132-144.

[Kementan] Kementerian Pertanian. 2017. Pedoman teknis kredit ketahanan pangan dan energi (KKPE). Kementerian Pertanian. Jakarta.

Kuwornu HJ, Isaac D, Ntow O, Brempong SA. 2012. Agricultural credit allocation and constraint analyses of selected maize farmers in Ghana. British Journal of Economics, Management and Trade. 2(4): 353-374.

Oboh VU, Ekpebu ID. 2011. Determinants of formal agricultural credit allocation to the farm sector by arable crop farmers in Benue State, Nigeria. African Journal of Agricultural Research. 6 (1):181-185. 
Rahmah UI. 2015. Analisis pendapatan usaha ternak ayam ras pedaging pada pola usaha yang berbeda di Kecamatan Cingambul Kabupaten Majalengka. Jurnal Ilmu Pertanian dan Peternakan. 3(1) : $1-15$.

Ratnasari R, Sarengat W, Setiadi A. 2015. Analisis pendapatan peternak ayam broiler pada sistem kemitraan di Kecamatan Gunung Pati Kota Semarang. Animal Agricultural Journal. 4(1): 47-53.

Sekyi EK. 2013. Impact of micro credit on rural farming activities: the case of farming communities within sunyani area. Journal Management Science and Engineering. 7(4): 23-29.

Sinaga B, Hartoyo S, Winandi R. 2013. Pengaruh pemanfaatan kredit dan bantuan modal terhadap keputusan produksi dan konsumsi serta dampaknya pada pendapatan dan pengeluaran Rumah Tangga Peternak. Laporan Akhir Penelitian Unggulan. Bogor: Institut Pertanian Bogor.

Sunarno, Purnomo SH, Rahayu ES. 2017. Factor affecting broiler production in wonogiri regency. American Scientific Research Journal for Engineering, Technology and Science. 1(28): 1-13.

Suprijatna E, Atmomarsono U, Kartasudjana R. 2005. Ilmu Dasar Ternak Unggas. Jakarta (ID): Penebar Swadaya.

Tamalluddin F. 2012. Ayam Broiler 22 hari Panen Lebih Untung. Jakarta: Penebar Swadaya.

Udoka CO, Mbat DO, Duke SB. 2016. The effect of commercial banks credit on agricultural production in Nigeria. Journal of Finance and Accounting. 4 (1): 110.

Vinanda F, Harianto, Anggraeni L. 2015. Risiko produksi ayam broiler dan preferensi peternak di Kabupaten Bekasi. Jurnal Manajemen dan Agribisnis. 13(1): 5058. 